\title{
Research on Adsorption, Permeation and Filtration Kinetics in Chemical Protection Technology
}

\author{
Dai Xuezhi ${ }^{1, a}$ \\ ${ }^{1}$ Institute of NBC Defense, Chinese PLA Army, Beijing, China
}

\begin{abstract}
The dynamic research status of three processes in chemical protection technology, namely, adsorption of steam by activated carbon, permeation of solvent by polymer film and filtering aerosol by cigarette paper were studied in this paper. The advantages and disadvantages of each model were analyzed, and the dynamic behaviors of the three processes were fully understood, which can effectively guide the research and development of chemical defense equipment and chemical defense of troops. It provides a reference for the study of the dynamic theory of the three processes.
\end{abstract}

\section{Introduction}

In chemical warfare or chemical terrorist attacks, the battle states of poisons are mainly vapor, aerosol, droplet and micropowder. Poisoning route can be respiratory tract inhalation, skin absorption, eating and drinking by mistake, etc. Compared with conventional weapons, the protection of chemical weapons is quite different, and the protection methods are also different. In order to reduce casualties, gas masks, skin protection equipment, dust filters and filter absorbers should be used to protect personnel ${ }^{[1]}$.

Activated carbon, cigarette filter paper and butyl rubber, as three basic materials for chemical protection, are widely used in protective equipment. Protective materials are mature in manufacturing and application technology, and have formed corresponding adsorption, permeation and filtration theories, but most of them belong to empirical models.

\section{Adsorption Theory of Activated Carbon Bed}

Activated carbon bed adsorption refers to the dynamic adsorption of toxic agents, organic vapors and other gases by carbon packing layer in airflow. Bed adsorption kinetics is to determine the utilization degree of adsorption capacity of a certain cross-section adsorption layer in any given time, and the relationship between the concentration of adsorbate in gas or liquid filled with space between particles and the realization conditions of adsorption process ${ }^{[2]}$.

Bed adsorption kinetics is to study the spatial distribution or temporal and spatial distribution of components between two phases when two phases move relatively in the system. All purification and recovery processes realized by means of solid sorbent are based on the principle of bed adsorption kinetics. Compared with static equilibrium adsorption, bed adsorption kinetics is a more complex process.

Up to now, the derivation of bed dynamics at home and abroad is mostly based on the assumption of parallel movement of adsorption waves, which is approximately obtained by conservative partial differential equations. The advantages and disadvantages of common dynamic models of activated carbon bed are described in the Table $1^{[3,4]}$.

Many researchers began to use mathematical models to solve more accurate numerical solutions to predict penetration time and concentration distribution. However, the mathematical model of the adsorption process of activated carbon bed is extremely complex, so some simplified treatment is needed.

Some researchers assume that:

1) The adsorbed gas obeys the ideal gas law

2) Ignoring the change of concentration and temperature caused by axial backmixing process, there is no gradient of concentration and temperature in the radius direction of adsorption column

3) There is only physical adsorption and no chemical reaction in the adsorption process

4) Using the local equilibrium model $(E Q)$, it is assumed that the instantaneous equilibrium can be achieved at any time between the main flow and the adsorption phase in the adsorption column

5) Ignore the pressure drop and temperature change in the activated carbon layer ${ }^{[5,6]}$.

a Corresponding author: 297896810@qq.com 
Table 1. Common adsorption kinetic models of activated carbon bed

\begin{tabular}{lll}
\hline \multicolumn{1}{c}{ Dynamic modle } & \multicolumn{1}{c}{ Equation } & \multicolumn{1}{c}{ Characteristic } \\
\hline Shilov equation & $t_{b}=\frac{a_{0}}{c_{0} v}(L-h)$ & $\begin{array}{l}\text { The equation can well estimate the relationship between anti-virus } \\
\text { time and packing thickness. However, the parameter } h \text { given by the } \\
\text { equation has no exact expression and cannot be associated with the } \\
\text { experimental conditions. }\end{array}$ \\
\hline Klotz equation & $I=I_{r}+I_{t}=\left(k_{8} v+\frac{1}{a} R e^{0.41} S c^{0.67}\right) \ln \frac{c_{0}}{c_{b}}$ & $\begin{array}{l}\text { The calculation of critical layer thickness is only applicable to the } \\
\text { case where the penetration rate is less than 20\%. The measured } \\
\text { penetration time of low boiling compounds (methanol, ethanol, } \\
\text { etc.) is much faster than that predicted by the equation }\end{array}$ \\
\hline Bohart-Adms model $\ln \left(\frac{c_{0}}{c_{t}}-1\right)=\ln \left(e^{\frac{K N_{0}}{v}}-1\right)-K c_{0} t$ & $\begin{array}{l}\text { It is successful to describe the exudation curve, but its theoretical } \\
\text { basis needs further study. On the assumption that the adsorption } \\
\text { kinetics at the initial stage is the first-order kinetics, the Bohart- } \\
\text { Adms bed adsorption model can be deduced from the mass } \\
\text { conservation equation. }\end{array}$ \\
\hline$t_{b}=\frac{a_{0}}{c_{0} v}\left[L-\frac{v \times 10^{3}}{k_{v}} \ln \left(c_{0} / c_{b}\right)\right]$ & $\begin{array}{l}\text { The whole exudation curve cannot be described, and the kv value } \\
\text { varies with the range of selected relative concentration. In many } \\
\text { cases, when the relative concentration is less than } 0.04, \text { it is not on } \\
\text { the same straight line, so the calculated kv value deviates greatly. }\end{array}$ \\
\hline
\end{tabular}

Table 2. Mathematical model of bed adsorption kinetics process

\begin{tabular}{|c|c|c|}
\hline Researcher & Mathematical method & Research contents \\
\hline Xiang Yangchun & $\begin{array}{l}\text { J function method } \\
\text { Orthogonal collocation } \\
\text { method }\end{array}$ & $\begin{array}{l}\text { The anti-virus time of activated carbon bed is estimated, and the anti- } \\
\text { virus time calculated by J function method is low and the error is large. } \\
\text { The calculated value of orthogonal collocation method is close to the } \\
\text { experimental value, but the calculated value is on the high side }\end{array}$ \\
\hline $\begin{array}{l}\text { Ning Ping, } \\
\text { Chen Yaxiong etc. }\end{array}$ & Finite difference method & $\begin{array}{l}\text { Compared with the experimental data, the error of predicting the } \\
\text { penetration time of VOCs into activated carbon layer is acceptable, but } \\
\text { the calculation is large and the accuracy is low compared with the } \\
\text { orthogonal collocation method }\end{array}$ \\
\hline Wei Feng & Online solution method & $\begin{array}{l}\text { The deviation between the calculated value and the experimental value } \\
\text { is small, and the calculation speed is higher than that of orthogonal } \\
\text { collocation method and finite difference method }\end{array}$ \\
\hline Yan Tian & Finite difference method & $\begin{array}{l}\text { The effects of volume flow rate, bed height and inlet concentration on } \\
\text { the kinetic curves of benzene and toluene adsorbed by fixed bed are } \\
\text { predicted. The calculated values of } \mathrm{c} / \mathrm{c} 0<0.8 \text { are in good agreement } \\
\text { with the experimental values, while the deviation of } \mathrm{c} / \mathrm{c} 0>0.8 \text { is large }\end{array}$ \\
\hline
\end{tabular}

Under the above assumptions, the mathematical model of bed adsorption kinetics is described by the following equations, namely, the material balance equation, adsorption kinetics equation and adsorption isotherm equation are:

$$
\begin{gathered}
u \frac{\partial y}{\partial z}+\varepsilon \frac{\partial y}{\partial \tau}+(1-\varepsilon) \rho \frac{\partial x}{\partial \tau}=0 \\
\frac{d x}{d \tau}=k\left(y-y^{*}\right) \\
y^{*}=f\left(x^{*}\right)
\end{gathered}
$$

$y$ in the above formula is the mass concentration of adsorbate in gas phase, $\mathrm{kg} / \mathrm{m}^{3} ; x$ is the adsorption capacity of adsorbate on activated carbon, $\mathrm{kg} / \mathrm{kg} ; u$ is the empty tower speed, $\mathrm{m} / \mathrm{s} ; \rho$ is particle density, $\mathrm{kg} / \mathrm{m}^{3} ; \tau$ is time, $\mathrm{s}$; $\varepsilon$ is the porosity of the bed. $y^{*}$ is the mass concentration of adsorbate in gas phase when reaching equilibrium, $\mathrm{kg} / \mathrm{m}^{3} ; k$ is mass transfer coefficient, $\mathrm{m}^{3} /(\mathrm{kg} \cdot \mathrm{s})$. The equilibrium concentration $\mathrm{y}^{*}$ is obtained by regression processing of adsorption isotherm data, and the $\mathrm{k}$ value is selected according to relevant data ${ }^{[7]}$.

The boundary condition of adsorption isotherm equation is $z=0 ; y=y_{i n} ; z=L ; \tau=0 ; 0 \leq z \geq L ; x=x_{0}$
As shown in Table 2, it compares the effects of different mathematical methods used by some researchers on analyzing the dynamic behavior of activated carbon bed ${ }^{[8]}$.

\section{Filter Process of Cigarette Paper}

Almost all the smoke filter layers in modern military gas masks are made of smoke filter paper, and most of the smoke filter layers have an "unfolded" surface. Filter paper filters solid and liquid aerosol particles, which is the technical way of filter unit. As early as before the end of World War II, the scientific basis of aerosol filtration had been initially formed. The interception, diffusion, inertia, gravity and charge effects of aerosol particles filtered by fiber have been clarified the theoretical relationship between transmission coefficient and air pressure drop has been clarified. The particle trapping efficiency of a single fiber can be calculated by the law of logarithmic penetration ${ }^{[9]}$.

The movement characteristics of aerosol particles determine that the fiber smoke filter mainly filters them through interception effect, inertia effect, diffusion effect, gravity effect and electrostatic effect, among which the 
first three effects are the most frequent ones, as shown in the figure 1 .

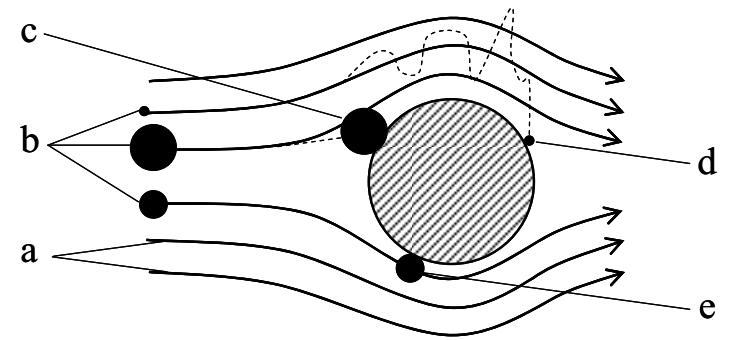

a- Airflow streamline; b- Aerosol particles; c- Inertia effect; d- Diffusion effect; e- Interception effect

Figure 1. Schematic diagram of the mechanism of fiber filtering particles

In a fiber filter, particles may be trapped due to one or several effects, which depends on particle size, density, fiber thickness, filling rate of smoke filter layer, airflow speed, etc ${ }^{[10-12]}$.

Aerosol filtration process is very complex. Although some theoretical principles of filtration have been well known, there is still a big gap between theory and experiment, as shown in the Table 3.

The core concept of classical fiber filtration theory is the capture efficiency of aerosol particles by a single fiber.
Based on this and certain assumptions, the logarithmic penetration law of the filter is derived from the conservation of aerosol particle number. The experiment of aerosol penetrating filter shows that the modeling of flow field around fiber, the simplification of particle motion equation, the coupling of various trapping mechanisms and the ideal condition of logarithm law may all lead to the deviation of theoretical calculation value of trapping rate from experimental results. Therefore, although the fiber filtration technology is widely used in industry and the filtration principle is well known, it is difficult to calculate the performance of the filter directly from the filtration theory. The filtration theory and model are mainly used for qualitative analysis and comparison, and a lot of design and development work is based on empirical equations ${ }^{[13,14]}$.

When aerosol passes through most filter materials for a long time, the capture efficiency and resistance change with time. In some cases, the structural changes in the filter are very slow, but the initial values of the decisive filter operating parameters $K$ and $\triangle p$ are often changed so rapidly and quite violently ${ }^{[15,16]}$. The secondary process in filter is caused by various reasons. The changes in this process are complex, the research is less, and the mathematical description based on clear physical images is lacking ${ }^{[17-19]}$.

Table 3. Development of aerosol filtration theory [20-26]

\begin{tabular}{|c|c|c|}
\hline Researcher & $\begin{array}{l}\text { Theoretical contribution } \\
\end{array}$ & Time \\
\hline Freundlich & $\begin{array}{l}\text { It is proposed that the maximum penetration rate of aerosol particles exists in the } \\
\text { radius range of } 0.1 \sim 0.2 \mu \mathrm{m} \text {. }\end{array}$ & 1926 \\
\hline Albrecht etc. & $\begin{array}{l}\text { It is the first to study the movement of particles in airflow through a single cylindrical } \\
\text { fiber, and establish the inertial mechanism of Albrecht particles, which is the basis of } \\
\text { the inertial movement of particles today. }\end{array}$ & 1931 \\
\hline Kaufmann & $\begin{array}{l}\text { In 1936, the concepts of Brownian diffusion motion and inertial deposition were first } \\
\text { applied to fiber filtration theory, and the mathematical formula of filtration action was } \\
\text { derived. }\end{array}$ & 1936 \\
\hline Langmuir & $\begin{array}{l}\text { It is considered that filtration is the collection of interception and diffusion, and the } \\
\text { minimum filtration efficiency of fiber is put forward. Founder of filtering theory. }\end{array}$ & 1942 \\
\hline Davies & $\begin{array}{l}\text { The filtration theory of isolated fiber theory is established. The whole particle capture } \\
\text { depends on the combination of various capture mechanisms, and the first study is the } \\
\text { most permeable particle size. }\end{array}$ & 1952 \\
\hline Kuwarbara & $\begin{array}{l}\text { The viscous flow field distribution theory influenced by adjacent objects makes the } \\
\text { trajectory calculation of particles around single fiber more accurate. }\end{array}$ & 1959 \\
\hline Friedlander & $\begin{array}{l}\text { The basic fluid boundary layer theory puts forward the most permeable particles in } \\
\text { the filtration process. }\end{array}$ & 1967 \\
\hline Payet etc. & $\begin{array}{l}\text { Considering the sliding of gas on a single fiber, the correction coefficient is } \\
\text { introduced into the classical theory, which makes the theory better coincide with the } \\
\text { experimental data. }\end{array}$ & 1992 \\
\hline Cai Jie & $\begin{array}{l}\text { The concept that interception effect is the extreme value of diffusion and inertia effect } \\
\text { is put forward. }\end{array}$ & 1993 \\
\hline Thomas & $\begin{array}{l}\text { The influence of "filter cake" or "coagulation" phenomenon on filtration efficiency is } \\
\text { studied, and the calculation model of filtration efficiency and pressure loss different } \\
\text { from clean filtration is put forward. }\end{array}$ & 2001 \\
\hline
\end{tabular}

\section{Penetration of Butyl Rubber}

Isolated skin protective equipment is made of dense polymer film material with extremely low air permeability, and the protective effect on toxic agents and other toxic chemicals depends on the anti-permeability of the material ${ }^{[27]}$. At present, butyl rubber cloth and chlorinated butyl rubber cloth are the main materials of our army's isolated anti-virus clothing.

Butyl rubber: The main chain (polyisobutylene) of linear polymers copolymer, which is mainly composed of isobutylene and a small amount of isoprene, has a spiral 
structure, and the huge methyl groups are arranged neatly and tightly on both sides, which can effectively prevent gas diffusion. Butyl rubber has reliable anti-virus performance and chemical stability. Chlorinated butyl rubber: A chlorine group is added to the butyl rubber, because chlorine atoms are added to the main chain, which can make the molecules compact and reduce less holes in the structural formula, so its structure is more compact than that of butyl rubber, which enhances the ability of preventing gas diffusion and has better antivirus ability.

The interaction process between poison droplets and polymers can be divided into spreading, infiltration and diffusion, swelling and dissolution, desorption and other stages, which can be studied by using the thermodynamics and kinetics theory of the interaction between ordinary droplets and polymers.

As early as 1921, British scholar H. Daynes, aiming at the diffusion process of gas molecules permeating polymer, based on certain initial boundary conditions and Fick's second diffusion law, deduced the unsteady and steady flux curve equations of permeation process, which was widely used in engineering technology to calculate diffusion coefficient and study the properties of gas molecules permeating materials. The Soviet scholar Ingrid Baoom obtained the same theoretical results for the one-dimensional diffusion process of poison penetration [12].

Experiments show that when the poison in liquid droplet or vapor state acts on the surface of polymer film, after a certain period of time, the poison seeps out from the back of polymer film. If the permeation process is under constant conditions, the equilibrium state will be reached after a long enough time, that is, the amount of poison permeated per unit time and area will remain constant. For this permeation process, Ingrid Baoom first deduced the permeation curve equation according to Fick's second diffusion law, and put forward four assumptions:

1) The toxic agent in contact with the front of the film is always excessive. At the moment of contact, the concentration of toxic agent on the surface with $x=0$ reaches $c_{\max }$ and remains $c_{\max }$ all the time;

2) If the poison penetrated into the back is removed in time (taken away by air), the concentration of poison at $x=\delta$ will always be zero;

3) Diffusion coefficient $D$ is constant and does not change with concentration;

4) The change of polymer film thickness $\delta$ in the permeation process can be neglected.

According to the hypothesis and permeation model, the permeation process of poison is a one-dimensional diffusion process for polymer film materials with uniform composition. Permeability curve equation is:

$$
Q=\frac{2 \delta c_{\max }}{\pi^{2}}\left[\frac{\pi^{2} D}{2 \delta^{2}} t-\frac{\pi^{2}}{12}-\sum_{n=1}^{\infty} \frac{(-1)^{n}}{n^{2}} e^{-n^{2} \pi^{2} \delta^{-2} D t}\right]
$$

In the formula, $\mathrm{Q}$ is the toxic dose per unit area in time $\mathrm{t}, \mathrm{g} / \mathrm{cm}^{2} ; \delta$ is material thickness, $\mathrm{cm} ; \mathrm{D}$ is diffusion coefficient, $\mathrm{cm}^{2} / \mathrm{s}$; cmax is the limit swelling value of film material in poison, $\mathrm{g} / \mathrm{cm}^{3}$.
More scholars have made an in-depth study on the permeation kinetics of toxic agents on polymer films.

Anthony et al. studied the penetration curve of HD simulant CEES on $0.838 \mathrm{~mm}$ butyl rubber, and found that the penetration time of CEES was $76.6 \mathrm{~min}$, and the diffusion coefficient was $2.61 \times 10-7 \mathrm{~cm}-2 / \mathrm{s}$. It was considered that the processing technology significantly affected the penetration time of materials ${ }^{[13]}$.

Walter Zukas et al. studied the permeation kinetics process of natural rubber composites with different proportions of HD simulant DCH soap. Surface chemical modification can improve the permeability resistance of materials and prolong the practical effect of natural rubber [28].

Donald studied the penetration process of HD and simulated agent CEPS on butyl rubber cloth, and obtained that the diffusion coefficient of CEPS was $1.2 \times 10-7$ $\mathrm{cm} 2 / \mathrm{s}$.

G. Unnikishna et al. studied the swelling process of benzene on natural rubber, rubber filled with carbon black and rubber filled with silica, evaluated the swelling process of benzene, toluene, p-xylene and trimethylbenzene on rubber filled with carbon black, and also investigated the effect of temperature on the swelling kinetics of trimethylbenzene on rubber filled with carbon black ${ }^{[15]}$.

China's biochemical protection research started relatively late. At present, there are mainly two types of isolated protective clothing, one is FFY-02 protective clothing with butyl rubber cloth as material, and the other is FFY-03 protective clothing with butyl chloride rubber cloth as material. At the beginning of 1960 s, China began to study the penetration law of poison in rubber materials. Wang Zhenmin research shows that the No.5 instrument can not only measure the anti-virus ability of isolated skin protective materials against toxic agents, but also study the permeation process of toxic agents, i.e., measure the quantitative relationship curve of the permeation amount of toxic agents on the back of the material with time increase, and calculate the permeation kinetic constantdiffusion coefficient D of toxic agents in isolated skin protective materials, and measure the diffusion coefficient of HD in natural rubber film with an order of magnitude of $10^{-7}$. Cao Ga and Wang Yanchao studied the anti-virus ability of polyethylene film and natural latex film to HD with different droplet sizes. They thought that the antivirus ability of materials was different with different droplet sizes, and found that the anti-virus ability increased with the decrease of droplets. Zhang Cailan discussed the changing rule of the anti-virus ability of natural rubber dry film with different thickness to HD with different droplet sizes. The experimental results show that natural dry film and natural latex film have the same anti-virus performance ${ }^{[16]}$. In his dissertation, Min $\mathrm{Xu}$ studied in detail the influence of butyl latex film material on the anti-virus ability of poison with different droplet sizes and different temperatures, and obtained empirical equations. Cui Junming used the theory of "blocking effect" to explain the interaction and action mechanism of poison droplets in the process of diffusion on the colloidal layer, and established a simple five-drop poison distribution method, which can test the anti-virus 
ability of skin defense materials against tiny droplets on the battlefield. Liu Jun studied the diffusion and desorption of HD in polyethylene film, and the experiment proved the correctness of desorption theory $[17,18]$.

Zhu Yongkang et al. used methyl salicylate as HD simulant, and pointed out that the penetration rate of methyl salicylate on butyl bromide glue increased with the increase of temperature. With the increase of kinetic energy of methyl salicylate and the thermal expansion of compound, the free volume of polymer increases due to the acceleration of thermal motion of segment. When the temperature is raised, the rate of forming holes large enough for methyl salicylate to pass through the film increases, and the diffusion coefficient of methyl salicylate/butyl bromide glue system is similar to HD. Thermal oxidation of butyl bromide rubber can improve permeability. The hardness of thermally aged samples increases, resulting in the decrease of final properties and chain network density. Compared with the unaged matrix, the solubility of methyl salicylate in thermally oxidized matrix decreases, which leads to the decrease of permeation.

\section{Conclusion}

As three key materials, activated carbon, cigarette paper and butyl rubber have been mature in manufacturing and application technology, and formed corresponding adsorption, permeation and filtration kinetic theories, but most of them have semi-empirical characteristics. Fully understanding the dynamic behaviors of the three processes, perfecting the existing theoretical models and studying the theoretical problems of military chemical protection technology can lay a foundation for the selection, evaluation, modification and research methods of protective materials.

\section{References}

1. He, Q T, Gao, H Z, Cui, J M. Technical basis of chemical protection [M]. Beijing: Ordnance Industry Press. 1996: 43-45.

2. Chakravarti M N, Dhar N R. Kolloid Z., 1927, 43: 377.

3. Moon D J, Chung M J. Adsorption equilibria of chloropentafluoroethane and pentafluoroethane on activated carbon pellet[J]. J. Chem. Eng. Data, 1998, 43: $861-8$

4. Bautista L F, Pinilla J. Adsorption isotherms of aspartame on commercial and chemically modified divinylbenzene-styrene resins at different temperatures[J]. J. Chem. Eng. Data, 2002, 47: 620627

5. Brunauer S, Deming L S, Deming E, Teller E. On a Theory of the van der Waals Adsorption of Gases[J]. J. Am. Chem. Soc., 1940, 62: 1723-1732

6. Yu F D, Luo L. Adsorption isotherms of VOCs onto an activated carbon monolith[J]. J. Chem. Eng. Data,
2002, 47: 467-473

7. Crickmore P J, Wojciechowski B W. Kinetics of adsorption on energetically heterogeneous surfaces[J]. J. Chem. Soc. Faraday I, 1977, 73: 12161223

8. Jaronic M. Physical adsorption on heterogeneous solid [M]. Beijing: Chemical Industry Press. 1997:35.

9. Friedlander, S. K. Theory of aerosol filtration. Ind. Eng. Chem. 1958, 50: 1161-1164.

10. Watson J M., Barson M G. Precise stactic and dynamic permeation measurement using acontinousflow cell[J]. Journal of Membrance Science, 1995, 106: 259-268.

11. G. Choudalakis, A.D. Gotsis. Permeability of polymer/clay nanocomposites: A review[J]. European Polymer Journal, 2009, 45: 967-984.

12. Fu X C, Shen W X. Physical Chemistry [M]. Nanjing; Higher Education Press, 2011: 889.

13. Bering B P, Serpinsky S K. Izv. Akad. Nauk SSSR, 1974, 74: 2427

14. Park S J, Donnet J B. Evaluation of the distribution function of adsorption site energies based on the Fermi-Dirac's law in a monolayer[J]. Journal of Colloid and Interface Science, 1998, 200: 46-51

15. Ma M M, Zhu H Y, Mao D. Estimation of molecular shape and size of military poison and its application [J]. Journal of Chemical Defense, 2000, 4: 50-53

16. D.W. Fan Kelei Weilun. Trans. Xu Yuanze, Zhao Delu and $\mathrm{Wu}$ Dacheng. Properties of polymers (estimation of properties and their relationship with chemical structure) [M], Beijing: Science Press, 1981

17. Mullins, B. J., Pfrang, A., Braddock, R. D., Schimmel, T., and Kasper, G. Experimental and theoretical evaluation of detachment force due to interfacial tension. Journal of Colloid and Interface Science. 2007, 2: 333-340

18. Liu D Q. Summary of air filtration technology research [J]. Environmental Science and Management, 2007,23 (5): 109-113.

19. Qin J H, Qing C. Process on property and application of metal porous materials[J]. Journal of Alloys and compounds 2016, 654: 39-44.

20. Li S C. Selection of filter material for dust collector $[\mathrm{J}]$. Building materials technology and application, 2001,4:17-205.

21. Davies, C. N. Viscous flow transverse to a circular cylinder. Proc. Soc., 1950, B63, 288-296.

22. Davies, C. N., Aylward, M. The photoelectric measurement of coal dust stains on filter paper[J]. Brit. J. appl. Phys. 1951 (3), 185-189.

23. Davies, C. N. The separation of airborne dust and particles. Proc. Inst. Mech. Eng. 1B 1952, (5), 185213.

24. Fang J J, Xu L J, He Y L. Development and application of personal protective equipment for chemical agents [J]. Research on Protective Equipment Technology, 2009, (4): 21-24 
25. Chen C X, Han B B. Study on the transmission behavior of small molecules in dense polymer membranes (I) Classification and description of diffusion behavior $[\mathrm{J}]$. Membrane Science and Technology 2000, 30(3): 1-5.

26. Cui J M. Study on the way of spreading poison to simulate battlefield exposure on isolation materials [J]. Journal of Chemical Defense, 1983, 2: 57-60.

27. Wang Z M. Evaluation of using No.5 instrument to study the permeation process of poison and measure the anti-virus ability of materials [D]. Beijing: Institute of Chemical Defense Command Engineering, 1964.

28. Cui J M. Study on the way of spreading poison on isolated materials and simulating battlefield exposure [J]. Journal of Chemical Defense, 1983(2): 57-68. 